\title{
Cystacyclin, a novel microbial metabolite with NGF mimetic activity
}

\author{
The Journal of Antibiotics (2013) 66, 743-744; doi:10.1038/ja.2013.78; published online 14 August 2013
}

Nerve growth factor (NGF) is known to have key roles in neural protection and repair of central and peripheral neurons. ${ }^{1}$ NGF was reported to ameliorate several neuronal dysfunction and injury in animal models, ${ }^{2,3}$ and has been applied to clinical trial. ${ }^{4}$ Because of its protein property, NGF is thought unsuitable for oral administration and insufficient for blood-brain barrier penetration. So far low-molecular-weight compounds having NGF mimetic activity have been screened and neurite-inducing compounds such as lactacystin ${ }^{5}$ and K-252a ${ }^{6}$ were isolated from microbial resources. A chemically synthesized compound of AIT012 was reported to enhance NGF-induced neurite outgrowth and has been applied to clinical trail. ${ }^{7}$ In this report we describe isolation of a novel NGF mimetic compound and show its physico-chemical properties and biological activities of the compound named as cystacyclin.

Rat pheochromocytoma cell line of PC12 was known to form neurite in response to NGF. For screening PC12 cells were inoculated into 96-well microplate and microbial cultured broths were applied. After 2 days incubation, neurite formation of the cells was observed visually with microscope. From about 30000 microbial cultured broths, 40 positive samples were selected. Human leukemia cell line of TF-1 was known to proliferate dependently on the factors such as NGF, granulocyte macrophage colony-stimulating factor or interlukin-3 in the medium. ${ }^{8}$ TF-1 cells were washed three times with the factor-deficient medium and inoculated into 96-well microplate with the same medium. The 40 samples selected in the PC12 cell assay were applied to the TF-1 cells and cellular proliferation was monitored with ${ }^{3} \mathrm{H}$-thymidine uptake activity. As a result, one positive sample that elicited the uptake activity was selected and a producing microbial strain was assigned to Streptomyces endus.

Active compound was purified from cultured filtrate with carbon adsorption, silica gel and Sephadex LH-20 column chromatography. The partially purified material was applied to Dowex50 $\left(\mathrm{H}^{+}\right)$at $\mathrm{pH}=3$ and neutralized with cyclohexylamine. Active compound as cyclohexylamine salt was crystallized in $\mathrm{H}_{2} \mathrm{O}$-acetone solvent and finally converted to sodium salt. From 50 liters of the culture broth $1.0 \mathrm{~g}$ of active compound was obtained in a form of colorless powder.

The active compound was soluble in $\mathrm{H}_{2} \mathrm{O}$ but insoluble in hexane, $\mathrm{CHCl}_{3}$ and EtOAc. It gave positive color in ninhydrin, tolidinechlorine and phosphomolybdic acid/sulfuric acid reaction. On silica gel TLC (Merck, Art. no. 5715) developed with $\mathrm{BtOH}-\mathrm{AcOH}-\mathrm{H}_{2} \mathrm{O}$ (4:1:2) the compound gave single spot at $R_{\mathrm{F}}=0.50 . \mathrm{UV}_{\max }(\mathrm{MeOH})$ was detected at $200 \mathrm{~nm}$ and IR absorptions $\left(\mathrm{KBr}, \mathrm{cm}^{-1}\right)$ were detected at $3400,2950,1735,1600$, 1400, 1300, 1145 and 1040. ${ }^{1} \mathrm{H}-\mathrm{NMR}$ $\left(200 \mathrm{MHz}, \mathrm{D}_{2} \mathrm{O}\right)$ signals were detected at $4.30(1 \mathrm{H}, \mathrm{dd}, J=4.5,7.8 \mathrm{~Hz}), 2.97(1 \mathrm{H}, \mathrm{dd}$, $J=4.4,13.6 \mathrm{~Hz}), 2.92-2.62(5 \mathrm{H}, \mathrm{m}), 2.50$ $2.10(3 \mathrm{H}, \mathrm{m}), 2.00(3 \mathrm{H}, \mathrm{s})$ and $1.81(1 \mathrm{H}, \mathrm{m})$. ${ }^{13} \mathrm{C}-\mathrm{NMR} \quad\left(200 \mathrm{MHz}, \mathrm{D}_{2} \mathrm{O}\right)$ signals were detected at 226.9 (s), $185.2(\mathrm{~s}), 179.9$ (s), $176.6(\mathrm{~s}), 57.5(\mathrm{~d}), 56.0(\mathrm{~d}), 52.6(\mathrm{~d}), 40.8(\mathrm{t})$, $37.9(\mathrm{t}), 33.6(\mathrm{t}), 28.0(\mathrm{t})$ and $24.8(\mathrm{q})$. Molecular formula was established as $\mathrm{C}_{12} \mathrm{H}_{15} \mathrm{NO}_{6} \mathrm{SNa}_{2}$ (347) based on HRFABMS $\left([\mathrm{M}+\mathrm{H}]^{+}, \quad 348.044\right)$ and ${ }^{13} \mathrm{C}-\mathrm{NMR}$ spectra. The structure of the compound

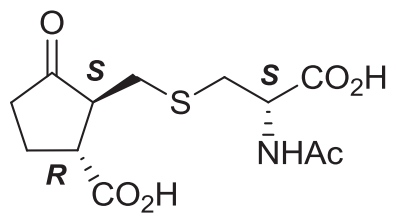

Figure 1 The structure of cystacyclin. was determined as shown in Figure 1. Absolute structural elucidation and total synthesis will be described elsewhere. The compound composes of $N$-acetyl-L-cysteine and 2-methylidene-3-oxo-1-cyclopentanecarboxylic acid and is designated as cystacyclin on the basis of the two moieties of the cysteine and the cyclopentanecarboxilic acid. The partial structure of cystacyclin is similar to sarkomycin, 2-methylene-3-oxocyclopentanecarboxylic acid isolated from microbial resources. ${ }^{9,10}$

Cystacyclin induced multiple-neurite formation of PC12 cell in a range of 2 to $20 \mu \mathrm{g} \mathrm{ml}^{-1}$. The morphological features of the neurite were similar to those induced by NGF. Cystacyclin enabled TF-1 cells to proliferate in the factor deficient medium. Between 3.2 and $25.0 \mu \mathrm{g} \mathrm{ml}^{-1}$ cystacyclin elicited ${ }^{3} \mathrm{H}$-thymidine uptake activity in a dose-dependent manner. The uptake activity increased time-dependently and concomitant increase of the cellular number was confirmed by microscopic observation. Cystacyclin at $5 \mu \mathrm{g} \mathrm{ml}^{-1}$ supported long-term TF-1 cell proliferation in the factor-deficient medium and maintained more than 10 passages without losing factor dependency. Similar to NGF cystacyclin supported survival and neurite outgrowth of rat sympathetic neurons.

Bioavailability of cystacyclin in oral administration was roughly between 15 and $20 \%$ with mice, rats and dogs. Oral or i.p. administration to mice at $500 \mathrm{mg} \mathrm{kg}^{-1}$ did not cause toxicity in behavior, body weight change, survival and autopsy 
observation. Daily oral administration for about 4 months at $100 \mathrm{mg} \mathrm{kg}^{-1}$ did not cause toxicity with mice. $\mathrm{LD}_{50}$ value of i.v. administration to mice was estimated over $4.1 \mathrm{~g} \mathrm{~kg}^{-1}$. Effects on rodent models of cisplatin-induced neuropathy and diabetic neuropathy with $\mathrm{db} / \mathrm{db}$ mutant mice will be reported elsewhere. A novel low-molecular-weight compound of cystacyclin is thought to be potential to treat neuronal dysfunction and injury.

\section{ACKNOWLEDGEMENTS}

We thank Dr Taka-aki Nishikiori, Masaya Sato, Chikako Kimura, Dr Hiroshi Sato, Akira Masuda, Kuniko Masuda, Takamichi Sato, Akihiro Tomura, Yoshiyuki Takayasu, Chieko Shibazaki-Seno, Mineaki Okada, Eiichi Kawano, Hirohumi Yokoyama, Iwao Nakamura, Dr Katsuhiko Sakitama, Masato Suwa, Noriko Asakawa, Dr Kyo-ichi Shibuya, Dr Glenn Friedman, Dr Xiuming Yang, Dr Mason M Yamashita and
Dr Dinah WY Sah for technical assistance and valuable discussion.

Tomio Morino, Masashi Nagai, Daisuke Komagata, Ayako Nakatani-Iida Masayuki Kitagawa, Takashi Harada and

Seiichi Saito

Pharmaceuticals Research Laboratories, Research and Development Group, Tokyo, Japan

E-mail: tomio.morino@nipponkayaku.co.jp

1 Softroniew, M. V., Howe, C. L. \& Mobley, W. C. Nerve growth factor signaling, neurprotection and neural repair. Annu. Rev. Neurosci. 24, 1217-1281 (2001).

2 Fischer, W. et al. Amelioration of cholinergic neuron atrophy and spatial memory impairment in aged rats by nerve growth factor. Nature 329, 65-68 (1987).

3 Kromer, L. F. Nerve growth factor treatment after brain injury prevents neuronal death. Science 235 214-216 (1987).
4 Apfel, S. C. Nerve growth factor for the treatment of diabetic neuropathy: what went wrong, what went right, and what does the future hold? Int. Rev. Neurobiol 50, 393-413 (2002)

5 Omura, S. et al. Lactacystin, a novel microbial metabolite, induces neurogenesis of neuroblastoma cells. J. Antibiotics 44, 113-116 (1991).

6 Glicksman, M. A., Forbes, M. E., Prantner, J. E. \& Neff, N. T. K-252a promotes survival and choline acetyltransferase activity in striatal and basal forebrain neuronal cultures. J. Neurochem. 64, 1502-1512 (1995).

7 Grundman, M. et al. A multicenter, randomized, placebo controlled, multiple-dose, safety and pharmacokinetic study of AIT-082 (Neotrofin) in mild Alzheimer's disease patients. Life Sci. 73, 539-553 (2003).

8 Chevalier, S. et al. Expression and functionality of the trkA proto-oncogene product/NGF receptor in undifferentiated hematopoietic cells. Blood 83, 1479-1485 (1994).

9 Umezawa, H., Takeuchi, T., Nitta, K., Yamamoto, T. \& Yamaoka, S. Sarkomycin, an anti-tumor substance produced by Streptomyces. J. Antibiotics (Tokyo) 6, 101 (1953).

10 Hill, R. K., Foley, P. J. Jr \& Gardella, L. A. The absolute configuration of sarkomycin. J. Org. Chem. 32, 2330-2335 (1967) 